\title{
Athletes' Perceived Use of Information Sources When Forming Initial Impressions and Expectancies of a Coach: An Explorative Study
}

\author{
Andrew J. Manley, lain Greenlees, and Jan Graydon \\ University of Chichester
}

\author{
Richard Thelwell \\ University of Portsmouth
}

\author{
William C.D. Filby \\ University of Brighton
}

\section{Matthew J. Smith \\ University of Chichester}

\begin{abstract}
The study aimed to identify the sources of information that athletes perceive as influential during their initial evaluation of coaching ability. University athletes $(N=538)$ were asked to indicate the influence of 31 informational cues (e.g., gender, body language or gestures, reputation) on the initial impression formed of a coach. Following exploratory factor analysis, a 3-factor model (i.e., static cues, dynamic cues, and third-party reports) was extracted. Mean scores revealed that although static cues (e.g., gender, race or ethnicity) were rated as relatively unimportant during impression formation, dynamic cues (e.g., facial expressions, body language or gestures) and third-party reports (e.g., coaching qualifications, reputation) were viewed by athletes as influential factors in the formation of expectancies about coaches. Such findings have implications for the occurrence of expectancy effects in coach-athlete relationships and the way in which coaches seek to present themselves.
\end{abstract}

People form initial impressions of one another in a host of social situations ranging from school classrooms (Jussim \& Eccles, 1992) to job interviews (Jussim, Coleman, \& Lerch, 1987). Expectancies of a target person or group will be developed depending on the nature of the impression that is formed (Miller \& Turnbull, 1986), and although these social interactions might be fleeting, the impressions and expectations initially formed might prove to be long lasting (Jussim \& Harber, 2005) and affect future interactions between perceiver and target. In the

Manley, Greenlees, Graydon, and Smith are with the School of Sport, Exercise \& Health Sciences, University of Chichester, Chichester, West Sussex, PO19 6PE, UK. Thelwell is with the Sport \& Exercise Dept., University of Portsmouth, Hampshire, P01 2ER, UK. Filby is with the Chelsea School, University of Brighton, Hillbrow, Eastbourne, BN20 7SR, UK. 
sport setting, studies involving officials (e.g., Frank \& Gilovich, 1988), coaches (e.g., Solomon, 2001), and athletes (e.g., Greenlees, Buscombe, Thelwell, Holder, \& Rimmer, 2005) illustrate that first impressions have the potential to influence perceivers' expectancies of targets. These expectancies might dictate the behavior of both perceiver and target, regardless of whether the formed belief is accurate or not (Horn, Lox, \& Labrador, 2001). The self-fulfilling prophecy is an example of such an expectancy effect.

Merton (1948) used the phrase the self-fulfilling prophecy to describe "a false definition of the situation evoking a new behavior which makes the originally false conception come true" (p. 195). The four-step expectancy cycle (e.g., Horn et al., 2001; Solomon, 2001) has been suggested as a model of how self-fulfilling prophecies can occur in sport. According to the four-step cycle, the process is as follows: (1) beliefs and expectancies about the target are adopted by the perceiver, (2) the perceiver behaves toward the target as if his or her expectancies are true, (3) the target interprets the perceiver's behavior toward them and behaves in accordance with this interpretation, (4) the perceiver sees the target's behavior as evidence for the accuracy of his or her initial impression (Becker \& Solomon, 2005). Although Horn et al. (2001) correctly point out that "all four steps in the sequence are essential if the self-fulfilling prophecy phenomenon is to occur in the athletic setting" (p.71), the first step in the process (i.e., the formation of beliefs and expectancies) has been largely neglected in the literature. The ability to pinpoint the cues that are most influential in expectancy formation could be helpful in developing strategies aimed at (1) limiting the negative impact of expectancies (e.g., athlete drop-out, performance decrements) and (2) maximizing the potential benefits (e.g., reducing an opponent's confidence in their ability to achieve a successful outcome) of presenting oneself in a positive way. Thus, there is value in obtaining a fuller understanding of how expectancies are formed in sport.

There have been previous attempts to classify the sources of information used in person perception in terms of the mode in which cues are presented. Cook (1971) categorized sources of information as either static or dynamic. Although static cues are defined as constructs that remain relatively stable over the course of short-term bouts of interpersonal interaction (e.g., physique, gender, age), dynamic cues are thought to be more changeable characteristics that might alter over short spaces of time (e.g., posture, facial expressions, body language). In the sport literature, Horn et al. (2001) examined how coaches form expectancies of their athletes and postulated that there are two main types of informational cues that coaches use. First, person cues (similar to Cook's static category) include information that remains relatively stable across the interaction between coach and athlete (e.g., socioeconomic status, race or ethnicity, gender, family background, attractiveness, physique). The second source of information, labeled performance information, encompasses a variety of cues including athletes' scores on physical tests, past performances and achievements of the athlete, direct observation of athletes' performance and behavior, and comments from other coaches regarding athletes' performance and behavior.

Solomon and colleagues (e.g., Becker \& Solomon, 2005; Solomon, 2001) proposed that dynamic or performance information could be separated into three distinct categories: personal (i.e., body language, facial expressions), performance (i.e., past achievements, physical test scores), and psychological cues (i.e., confidence, anxiety). In fact, Becker and Solomon (2005) found that an athlete's 
psychological characteristics were perceived by coaches to be the most influential sources of information during expectancy formation. It can be contended, however, that psychological cues such as confidence and determination are themselves beliefs that are derived from information that is available from the environment rather than sources of information in their own right. Thus, although a coach might base his or her expectancies for performance on judgments of the psychological qualities of an athlete, these psychological judgments will, in turn, be developed from more observable cues (e.g., body language, eye contact). Becker and Solomon allude to this point when they state, "[Although] personal and performance cues can be objectively interpreted, psychological cues are intangible and [might] be more difficult to assess." (p. 252). Observable cues such as ethnicity (e.g., Razran, 1950), exercise status (e.g., Shields, Brawley, \& Martin Ginis, 2007), and even reports of music preferences (e.g., Rentfrow \& Gosling, 2006) might be used by perceivers to form expectancies of the intangible psychological characteristics that a target might possess.

Previous research has also attempted to measure the level of influence that each type of cue has on the expectancy-formation process. Cook (1971) stated that although dynamic cues are more likely than static cues to allow for the formation of accurate judgments, the latter are still frequently used during expectancy formation. Despite the potential for static informational cues to influence expectancies, however, dynamic behavioral cues are considered the major determinant of perceivers' impression formation (Jussim, 1993). Jussim et al. (1987) provided support for this contention when they found that behavioral cues (i.e., clothing and speech style) were used more than race as a basis for evaluations of the job suitability of applicants. Horn et al. (2001) also stated that behavioral cues are more likely to result in the formation of accurate expectancies, whereas Becker and Solomon (2005) reported that coaches do not view static cues as particularly salient sources of information when developing expectancies of athlete ability. Such evidence seems to suggest that expectancy formation is influenced more heavily by dynamic behavioral cues than static attributes. Despite apparent agreement that expectancies based on behavioral cues are more influential and have greater predictive validity than expectancies founded on static sources of information, research has demonstrated the importance of static cues in impression formation. In both sport and nonsport settings, informational cues such as gender (Jacobs \& Eccles, 1992), race (Jowett, Frost, \& Timson-Katchis, 2006), and physique (Hash, Manna, Vogel, \& Bason, 2003) have been shown to shape perceivers' expectancies of a target, suggesting that static cues might also influence expectancy formation.

Moreover, there is sparse research that has examined athletes' use of information when forming impressions of their coach. Although athletes' affective and attributive responses toward coaches have been studied with specific reference to cues such as differences in race and ethnicity between coach and athlete (Jowett et al., 2006) and the coach's use of humor (Grisaffe, Blom, \& Burke, 2003), research scrutinizing the particular cues that athletes use when forming expectancies and attitudes toward their coach has been neglected. A recent study by Lubker, Watson, Visek, \& Geer (2005) is the closest example of such an investigation. The study explored the way in which athletes' first impressions of a sport psychologist impacted their subsequent expectancies about the target. Athletes rated their first impressions of 11 psychological enhancement consultants (PECs), whereby the 
clothing (i.e., athletic vs. academic), physique (i.e., lean vs. large build), gender, and ethnicity (i.e., White vs. African American) of PECs were manipulated. Athletes also rated the extent to which each variable influenced their ratings. Results showed that when PECs were White and male, those with lean build and academic dress were rated highest on personality traits (i.e., trustworthy, friendly, sensitive, sense of humor, good communicator). Ratings of sport knowledge were highest for lean athletically dressed PECs and lowest for PECs with academic dress and large build. Moreover, athletes reported that they were significantly more likely to seek the services of PECs with a lean physique than large PECs, regardless of clothing type. In all, despite findings that female PECs were rated significantly higher on personality traits than male PECs and that the ethnicity of athletes seemed to influence impressions to a certain extent, the overall data suggested that physique and clothing were cues that influenced athletes' expectancies to a greater extent than gender and race.

Lubker and colleagues (2005) have highlighted the possibility that certain impression cues are more likely than others to influence athletes' expectancies of those they collaborate with in the sporting context. So it is important that coaches are made aware of which sources of information are most salient for the athlete when developing expectations. This knowledge should enable the coach to exert more control over the impression they want to create and ultimately facilitate more effective coach-athlete interactions. The extent to which athlete preferences in forming expectancies of coaches are understood has important implications regarding the way in which the coach-athlete relationship is allowed to develop. As a result, the aim of this study is to examine the observable cues that athletes deem influential when developing expectancies of a coach. In addition, whereas the experiment conducted by Lubker et al. limited the manipulation of stimuli to cues that are relatively constant during short-term interactions, the current study sought to examine the role of more dynamic and unstable sources of information such as body language and posture. The inclusion of such cues is more reflective of the wide range of informational sources that might be presented in naturalistic encounters between coach and athlete.

A secondary aim of this study is to examine the extent to which demographic differences between performers determines the cues that are processed when forming impressions of a coach. Warr and Knapper's (1968) schematic model of person perception proposes that the information that is selected during person perception not only determines the nature of affective, attributive, and expectancy responses to a target, but also varies depending on perceivers' stable characteristics (i.e., their dispositions or personality traits that tend to be fairly robust across a range of situations). Because gender, type of sport, and level of participation can be categorized as stable characteristics, the model suggests that such factors might influence the formation of athletes' expectancies. Just as these characteristics have been suggested as moderating factors in athletes' preferred leadership style (Chelladurai, 1990), demographic background might determine the cues athletes use during initial impression formation. Thus, the current study will examine the effects of gender, type of sport, and level of participation on athletes' reports of the cues they deem to be most influential when forming initial impressions of a coach. 


\section{Method}

\section{Participants}

A total of 538 athletes, recruited from four universities in southeast England, volunteered to take part in the current study. Four volunteers did not fully complete the questionnaire, however, and their data were excluded from the analysis. The remaining 534 participants (Mean age $=20.33$ years, $S D=4.07$ ) consisted of 334 males $(62.5 \%)$ and 200 females $(37.5 \%)$ with a mean of 9.84 years $(S D=4.26)$ experience in their primary sport. Ninety-five percent of participants $(n=508)$ were White, with the remaining $5 \%$ consisting of Black African $(n=12)$, Asian $(n=8)$, Hispanic $(n=2)$, and mixed race $(n=4)$ athletes. Although participants were predominantly British $(92.9 \%)$, other nationalities were represented. Natives of various European countries (3.6\%), America and Canada (1.7\%), Australia and New Zealand $(1.3 \%)$, and China $(0.6 \%)$ were included in the sample. About two thirds of athletes $(60.6 \%)$ reported primary participation in team sports, and participation in individual sports was reported by $38.8 \%$ of athletes. The remaining $0.6 \%$ of participants $(n=3)$ did not specify a primary sport. Most athletes reported their highest level of participation to be at either regional or county level $(42.7 \%)$ or representing their university or club $(34.6 \%)$. Almost a fifth $(18.5 \%)$ of athletes had experience at either the national or professional level, and $3.2 \%$ of participants described themselves as recreational athletes. The highest level of performance was not specified by $1 \%$ of the population sample.

\section{Measures}

Athlete Demographic Questionnaire. Athletes' background information was obtained via athlete demographic questionnaires. Age, gender, race or ethnicity, nationality, primary sport, number of years experience in primary sport, highest level of participation, age during highest level of participation, and number of years experience at highest level were obtained.

Information Sources Scale. The Information Sources Scale (ISS) was developed as a means of investigating which impression cues athletes perceive to be most important when forming an initial impression of their coach. Following examination of a number of sources (e.g., Argyle, 1983; Cook, 1971; DePaulo, 1992; Knapp $\&$ Hall, 2002) concerning person perception and the cues employed during initial impression formation, a primary list of 28 items was constructed. We considered including the psychological cues outlined by Becker and Solomon (2005) given coaches' reported reliance on such prompts when assessing athlete ability. It was decided, however, that these items did not represent observable cues that might be encoded at the earliest point of social interaction. Because the current study was limited to the examination of such observable information sources, psychological cues were not included in the ISS. Men $(n=9)$ and women $(n=4)$ athletes from the University of Chichester (mean age $=24.85$ years, $S D=3.11$; mean sport experience $=12.00$ years, $S D=4.93$ ) volunteered to scrutinize the list of items and suggest any sources of information not mentioned that they might use when forming a first 
impression of a coach. Qualitative analysis of participant responses led to the addition of 3 items-language, clarity of voice, and presence or absence of assistant - to the ISS. A full list of the items used in the ISS can be seen in Table 1.

\section{Table 1 Items Athletes Use to Form Expectancies of Their Coach}

\begin{tabular}{lcc}
\hline Item & $\boldsymbol{M}$ & $\boldsymbol{S} \boldsymbol{D}$ \\
\hline Coaching experience & 5.56 & 1.13 \\
Clarity of voice & 5.43 & 0.95 \\
Success rate & 5.33 & 1.12 \\
Body language or gestures & 5.22 & 1.05 \\
Language (e.g., simple, technical, etc.) & 5.15 & 1.09 \\
Skill level & 5.15 & 1.20 \\
Eye contact & 5.14 & 1.17 \\
Equipment & 5.05 & 1.19 \\
Qualifications & 5.03 & 1.30 \\
Playing experience & 4.93 & 1.30 \\
Reputation & 4.88 & 1.35 \\
Posture & 4.53 & 1.33 \\
Speed of speech & 4.50 & 1.20 \\
Tone of voice & 4.50 & 1.39 \\
Clothing & 4.47 & 1.35 \\
Personal space or distance & 4.25 & 1.28 \\
Odor & 4.16 & 1.56 \\
Facial expressions & 4.12 & 1.35 \\
Touching behavior & 3.90 & 1.35 \\
Presence or absence of assistant & 3.81 & 1.48 \\
Physique or body type & 3.77 & 1.42 \\
Age & 3.26 & 1.51 \\
Social status & 3.25 & 1.37 \\
Accent of voice & 3.19 & 1.37 \\
Items of jewelry & 2.99 & 1.52 \\
Gender & 2.94 & 1.64 \\
Wearing of glasses or sunglasses & 2.76 & 1.33 \\
Attractiveness & 2.72 & 1.51 \\
Hairstyle & & 1.35 \\
Nationality & 1.52 \\
Race or ethnicity & \\
\hline & 2.59 \\
\hline
\end{tabular}


The method of rating the items included as part of the ISS was adapted from the Solomon expectancy sources scale (Becker \& Solomon, 2005). Each cue was evaluated for its appropriateness regarding the following declaration: "When forming an initial impression of a coach, is a major source of information that influences my impressions." Each item listed was used in turn to complete the sentence. Ratings for each cue were provided using a 7-point Likert scale ranging from 1 (very strongly disagree) to 7 (very strongly agree). The ISS also afforded respondents the opportunity to suggest any further sources of information not listed that might influence their initial impressions of a coach.

\section{Procedure}

Participants were recruited over a period of approximately 4 months. Those who described themselves as athletes currently participating in sport were provided with the athlete demographic questionnaire, ISS, and a consent form. Questionnaires were distributed to athletes during lectures or seminar classes and were completed in the presence of one of the authors so that any questions could be answered. The questionnaires took approximately 10-20 min to complete. Once the questionnaires were fully completed, athletes were thanked for their participation.

\section{Data Analysis}

Mean scores for items on the ISS were analyzed in an attempt to identify the sources of information that athletes deem most influential when forming expectancies of their coach. Exploratory-factor analysis (EFA) of ratings obtained from the ISS was also conducted to determine the collective factors associated with the cues athletes reported to be influential in expectancy formation. For the factor analysis, principalcomponent analysis was the extraction method used, and the varimax method of rotation was employed. MANOVA and follow-up ANOVA tests were performed on data obtained from the ISS with the aim of identifying any differences in ratings that might have occurred as a result of variations in demographic background between athletes (i.e., gender, type of sport, level of participation).

\section{Results}

\section{Descriptive Statistics}

The main purpose of the current study was to identify the cues that influence the formation of athletes' expectancies of their coach. Table 1 displays mean scores and standard deviations for items included in the ISS. Data show that although coaching experience, clarity of voice, success rate, and body language or gestures were rated highly by athletes as cues that might influence the development of initial impressions regarding their coach, cues such as race or ethnicity, nationality, hairstyle, and attractiveness received low athlete ratings in terms of the extent to which they were perceived to affect the formation of expectancies. Five of the nine items $(55 \%)$ that were given a mean rating of 5 or above could be categorized as static cues (e.g., skill level, equipment, etc.), whereas the remaining four sources of information could be more appropriately classified as dynamic behavioral cues 
(e.g., language used, eye contact, etc.). In contrast, of the 13 items that obtained a mean rating of less than 4 (i.e., below the midpoint in a 7-point rating scale), $69 \%$ $(n=9)$ could be classified as static cues and included items such as physique/body type, age, social status, and gender. Thus, the mean ratings for items included in the ISS indicated that athletes might use information from dynamic behavioral cues to a greater extent than static sources of information when forming initial impressions and expectancies of a coach. To examine this contention more fully, EFA of the data were conducted.

\section{Data Reduction}

The Kaiser-Meyer-Olkin (KMO) statistic was computed as a test of sampling adequacy before proceeding with the EFA. For analyses regarding the ISS, KMO was .85. This value was above the recommended value of .60 required to proceed with the EFA (Garson, 2006). Pearson's product moment correlations were conducted for items included in the ISS to check for multicollinearity. According to Tabachnick and Fidell (1996), bivariate correlations of greater than .70 are indicative of multicollinearity. Examination of the correlation matrix revealed multicollinearity between nationality and race or ethnicity $(r=.77)$. Stevens $(1996)$ suggests that an effective method of combating multicollinearity is to combine variables that are highly correlated to form a single measure. Hence, the ratings for nationality and race or ethnicity were pooled to form a single variable for race or ethnicity.

Factors were assessed according to four main determinants: Kaiser's criterion (i.e., eigenvalues greater than 1.0), examination of the scree plot, scrutiny of variable means (i.e., large differences between variable means indicate statistical rather than substantive bases of attribution), and analysis of residual values (i.e., the larger the number of nonredundant residuals with absolute values greater than .05 , the greater the doubt in the extracted model). After principal-components analysis with orthogonal (varimax) rotation, 7 factors with eigenvalues greater than 1.0 were initially extracted. Examination of the scree plot, variable means, and residual values (31\% nonredundant), however, meant that a three-factor model of information sources was suggested, which explained approximately $42 \%$ of the cumulative variance. Defining variables of each factor were characterized as those with factor loadings above .40 (Garson, 2006). The factors, associated variables, and rotated factor loadings are listed in Table 2.

The sources of information within the first factor were defined as static cues and accounted for $24.3 \%$ of the variance. Factor loadings dictated that gender, race or ethnicity, age, hairstyle, attractiveness, accent of voice, and social status should be grouped together. The second component, dynamic cues, accounted for $9.8 \%$ of the variance and included eye contact, tone of voice, facial expressions, posture, body language or gestures, clarity of voice, and language. The third extracted factor consisted of 5 variables: coaching experience, success rate, qualifications, playing experience, and reputation. This component was labeled third-party reports and accounted for $7.8 \%$ of the variance. Examination of variable means indicated that although athletes reported low use of static cues when forming initial impressions of a coach, dynamic cues and third-party reports were deemed much more influential in determining an athlete's impression formation of a new coach. 


\section{Table 2 Types of Cues Athletes Use When Forming Expectancies} of Their Coach

\begin{tabular}{|c|c|c|}
\hline Identified factor & Associated variables & $R F L$ \\
\hline \multirow[t]{7}{*}{ Static cues } & Gender & .844 \\
\hline & Race or ethnicity & .801 \\
\hline & Age & .744 \\
\hline & Hairstyle & .665 \\
\hline & Accent of voice & .561 \\
\hline & Attractiveness & .542 \\
\hline & Social status & .417 \\
\hline \multirow[t]{9}{*}{ Dynamic cues } & Eye contact & .688 \\
\hline & Tone of voice & .665 \\
\hline & Facial expressions & .661 \\
\hline & Posture & .621 \\
\hline & Body language or gestures & .566 \\
\hline & Clarity of voice & .556 \\
\hline & Language (e.g., simple, technical, etc.) & .505 \\
\hline & Motivational climate or coaching style ${ }^{\mathrm{a}}$ & - \\
\hline & Professionalism ${ }^{\mathrm{a}}$ & 一 \\
\hline \multirow[t]{6}{*}{ Third-party reports } & Coaching experience & .846 \\
\hline & Success rate & .793 \\
\hline & Qualifications & 689 \\
\hline & Reputation & .547 \\
\hline & Playing experience & .525 \\
\hline & Significant others ${ }^{\mathrm{a}}$ & - \\
\hline
\end{tabular}

Note. $R F L=$ rotated factor loading. ${ }^{\text {a }}=$ Additional items extracted after conceptual analysis.

In addition to items that were included as part of the ISS, $13.9 \%$ of all participants $(n=74)$ provided additional informational cues that they considered influential when forming an initial impression of a coach. Conceptual analysis of these data was conducted using guidelines proposed by Krippendorff (1980). These guidelines suggest that qualitative data should be coded into meaningful units of information so that certain characteristics of the text can be categorized with respect to the specific research question. Three main themes were identified from the cues suggested: motivational climate or coaching style, professionalism, and significant others (i.e., athletes' perceptions of the nature of relationships between the target coach and other individuals in the sport setting).

Motivational climate or coaching style was the construct to which most of the reported items seemed to relate $(n=46)$. A large number of responses in this category seemed to suggest that the athletes generally valued a democratic style of 
coaching. By identifying key words and coding them relative to the context in which they were conveyed, cues that were suggested included the extent to which the coach displays behavior that would lead them to be perceived as friendly, understanding, fair, supportive, and approachable $(n=28)$. Eleven participants also suggested that the extent to which the coach "socializes" with athletes outside the coaching environment is a potentially influential source of information. Some athletes $(n=$ 7), however, proposed that more autocratic coaching behavior such as maintaining control and demanding respect are cues that might influence their expectancies. Because these cues are descriptions of coaching behavior, motivational climate or coaching style is included in Table 2 under dynamic cues.

The second main theme that was extracted from the conceptual analysis of additional cues suggested by participants was labeled professionalism, and there were 13 responses grouped into this category, which included organization of training sessions $(n=4)$, punctuality and timekeeping $(n=3)$, the way the coaches introduced themselves and others $(n=4)$, and their use of swear words $(n=2)$. Again, in Table 2, professionalism has been placed under the category of dynamic cues because the additional factors cited in this context can be most appropriately described as behavioral sources of information.

The third theme extracted after conceptual analysis of participants' suggestions was classified as significant others $(n=13)$, and this item is included in Table 2 under third-party reports. Cues categorized under significant others included contacts with other coaches and support staff $(n=3)$; opinions and views of the target coach from the perspective of other coaches, support staff, and athletes $(n=4)$; the level of past athletes or the current team with whom the coach was working $(n=$ $4)$; and the level of demand for the coach's services $(n=2)$. There were two other cues reported as potential influences on the formation of expectancies regarding a coach (i.e., use of video analysis and facilities used). It was decided, however, that equipment, which was already included as an item on the ISS, was a sufficient definition to cover such aspects.

The conceptual analysis of additional influential cues suggested by participants provides further support for the three-factor model extracted via EFA. Additional items were classified as either dynamic cues (i.e., motivational climate or coaching style, professionalism) or third-party reports (i.e., views from significant others), with no suggestion from athletes' self-reports that the ISS was missing static cues that might be influential when forming an impression of a coach. Thus, the conceptual analysis reinforces the results of the EFA that athletes appear to regard dynamic cues and third-party reports as more influential than static cues when impressions and expectancies of a coach are initially created.

\section{Effect of Gender, Type of Sport, and Level of Participation}

An overall rating for each component extracted from the EFA was calculated by adding the ratings of individual items within each factor. Each relevant factor was then classified as a single dependent variable in the MANOVA that followed. Before the MANOVA was conducted, cases with missing data (i.e., no rating provided for items relating to extracted factors, primary sport or highest level of participation not specified) were omitted from the data sample. In addition, participants who stated their highest level of participation was recreational were not included in the 
analysis because an inadequate frequency of such responses $(n=17)$ was recorded. Participants who had spent less than 1 year at their highest level of participation were also excluded because it was reasoned that such athletes had not spent sufficient time interacting with coaches at that level. Thus, a total of 63 cases were omitted. The remaining 471 cases were included in the MANOVA.

No significant main effects were found for gender (Wilks's Lambda ${ }_{3,457}=$ $1.00, F=0.79, p>.05, \eta^{2}=.01$ ), type of sport (Wilks's Lambda ${ }_{3,457}=0.99, F=$ $1.35, p>.05, \eta^{2}=.01$ ), or level of participation (Wilks's Lambda ${ }_{6,914}=0.97, F=$ $2.09, p>.05, \eta^{2}=.01$ ) with regard to the informational cues athletes use to form initial impressions of their coach. In addition, the MANOVA did not reveal any significant interaction effects between the independent variables (Gender $\times$ Type of sport: Wilks's Lambda ${ }_{3,457}=1.00, F=0.49, p>.05, \eta^{2}=.003$; Gender $\times$ Level of participation: Wilks's Lambda ${ }_{6,914}=0.98, F=1.27, p>.05, \eta^{2}=.01$; Type of sport $\times$ Level of participation: Wilks's Lambda ${ }_{6,914}=0.99, F=0.84, p>.05, \eta^{2}=$ .01 ; Gender $\times$ Type of Sport $\times$ Level of Participation: Wilks's Lambda ${ }_{6,914}=0.98$, $F=1.97, p>.05, \eta^{2}=.01$ ). This reveals that there is general consensus between athletes regarding the cues that are deemed to be most influential when forming expectancies, regardless of gender, sport type, and participation level.

\section{Discussion}

The aim of this study was to examine the observable cues that might be used when athletes form first impressions of a coach. According to mean ratings obtained using the ISS, coaching experience, clarity of voice, success rate, and body language or gestures were the cues perceived as most influential in shaping an athlete's initial impression of a coach. These findings support previous reports that coach experience (Solomon, DiMarco, Ohlson, \& Reece, 1998), tone of voice or speech style (Jussim et al., 1987), success rate (Miki, Tsuchiya, \& Nishino, 1993) and body language (Greenlees et al., 2005) might be instrumental in expectancy formation in sport. Furthermore, the high mean rating for clarity of voice supports work that has claimed good communication skills are critical to coaching success (e.g., Crisfield, Cabral, \& Carpenter, 1999). Consequently, clarity of voice could be suggested to be a valid cue with regard to evaluating coaches' communication skills and ultimately their coaching ability. In contrast, race or ethnicity, nationality, hairstyle, and attractiveness received low mean ratings, suggesting that athletes view these cues as less influential in the formation of expectancies of their coach. These findings might indicate that athletes are aware of and adhere to the suggestion (Cook, 1971; Horn et al., 2001; Jussim, 1993) that accurate judgments are more likely when based on dynamic behavioral cues as opposed to static sources of information.

EFA of athlete feedback also yielded a three-factor model regarding the informational cues that athletes attend to when forming an initial impression of their coach. The three components extracted were labeled static cues, dynamic cues, and third-party reports. Static cues (i.e., gender, race or ethnicity, age, accent of voice) are more stable over time and generally uncontrollable, whereas dynamic cues (i.e., eye contact, tone of voice, facial expressions, body language or gestures) are episodic behaviors that are more malleable. Although certain static cues (e.g., age, accent of voice) are amenable to change over time, however, such cues are 
considered here in the context of initial short-term interactions between coach and athlete (e.g., minutes, hours, days) as opposed to long-term periods of contact (e.g., weeks, months, years). These first two categories match Cook's (1971) classification that static and dynamic cues are the two main sources of information that people use when forming impressions and expectancies of others.

Third-party reports (i.e., coaching experience, success rate, qualifications, reputation) are also clearly defined by the factor label and consist of information that is conveyed to the perceiver (either verbally or in writing) via a third party. This third grouping provides an addition to Horn and colleagues' (2001) dual classification of informational cues. Although cues categorized as static in the current study are a good match for the person cues suggested by Horn et al., performance information, as they defined it, seems to encompass both dynamic behavioral cues, which might be witnessed during direct observation of the target (e.g., facial expressions, posture) and third-party reports, which might include the opinions of other athletes or coaches. The fact that the current study revealed that dynamic cues and third-party reports are two distinct sources of information leads us to suggest that the two-factor model as proposed by Horn et al. might warrant expansion. It is important to emphasize, however, that because the current study was conducted at an explorative level, further research is required to examine this conclusion. The conceptual analysis also provided support for the contention that athletes regard dynamic cues and third-party reports as more influential than static cues when forming initial expectancies of a coach. Given the small sample of athletes who provided additional data and the fact that these responses were not included as part of the KMO test, however, such support requires more detailed investigation.

Mean scores indicated that whereas athletes view dynamic cues and third-party reports as influential in the creation of expectancies of coaches, static cues were deemed to have less impact. These results support previous suggestions (Becker \& Solomon, 2005; Cook, 1971; Horn et al., 2001; Jussim, 1993; Jussim et al., 1987) that although static cues influence expectancies regarding personality and behavior, dynamic behavioral cues seem to be the major determinant of a perceiver's impression formation. Such findings have important implications for the development of coaching guidelines and models of best practice. For instance, it appears that factors out of the coach's control (e.g., gender) are deemed less influential than controllable cues (e.g., body language) in terms of the impact they have on the expectancy formation of athletes. This would suggest that coaches have a great deal of control over the expectancies that athletes form of them.

The implication that third-party reports outweigh static cues in terms of their perceived impact on expectancy formation also supports the findings reported by Plunkett, Kohli, and Milad (2002). Plunkett and colleagues found that although female patients initially based their preference for a doctor on gender (i.e., female doctors were initially preferred), this static cue became much less salient when patients were asked to consider the doctor's reported reputation (i.e., experience, bedside manner, and competency). Nevertheless, a large number of studies support the potential influence of static cues such as race or ethnicity (e.g., Jowett et al., 2006), gender (e.g., Jacobs \& Eccles, 1992), and body type or physique (e.g., Hash et al., 2003) on expectancy formation. There are a number of explanations that might account for the fact that the results of the current study contradict such findings. 
First, there is the question of reliability regarding the data collection methods employed in this study. Because the ratings were based solely on athlete self-report, certain judgment biases might have influenced the overall findings. For instance, it is possible that participants feared they would be labeled sexist or racist if they rated gender or race or ethnicity as a highly influential factor regarding their impression formation of a coach (Jussim et al., 1987). Although it was made clear to participants that all responses would remain confidential, the athletes might still have been disturbed by their own thoughts regarding the possibility that their expectations of others could be influenced by such controversial cues (Turiel, 1983). To combat such cognitive dissonance and convince themselves of their good nature, athletes might have provided low ratings for certain items. Guyll and Madon (2003) reported examples of such self-induced social conformity and suggested that the need to maintain a positive self-schema might override the desire and motivation to provide a truthful response. Further scrutiny of the effects of social conformity on impression formation is required before such a contention can be confidently accepted.

Second, self-report ratings might not accurately reflect the cues that athletes use when forming expectancies because it is possible that the athletes themselves might be unaware of their encoding of certain cues. Previous research (Chen \& Bargh, 1997) has shown that cues presented outside the consciousness of the perceiver are still powerful enough to influence subsequent thought and behavior. Chen and Bargh found that the processing of informational cues and subsequent behavior can be unconscious and that unintentional expectancy effects might develop as a result. Hence, athletes might unintentionally use static cues such as race or ethnicity, gender, and attractiveness and consequently base expectancies of their coach on information that is processed subconsciously. The potential influence of cues presented outside of the perceiver's consciousness has not been examined in a sporting context. Future research designed to compare the strength of expectancies developed as a result of consciously and subconsciously presented stimuli would be useful in attempting to further understand the processes involved in the expectancy formation of athletes.

According to the ratings obtained in the current study, athletes believed that third-party reports were highly influential sources of information with regard to expectancy formation, a finding that might be explained by the notion that such cues could be viewed as less susceptible to subjective bias. It has been suggested (Jussim \& Eccles, 1992; Stone, Perry, \& Darley, 1997) that less objective criteria (e.g., perception of static cues via photographs and videos) might be more subject to facilitating inaccurate expectancies or perceptual biases than more subjective cues (e.g., provision of concrete statistics and quantitative values via third-party reports) when used as a basis for evaluation of a person's ability. This might be because objective cues such as statistics and scores are less open to the perceiver's own interpretation than a subjective aspect such as attractiveness (Stone et al., 1997). Thus, athletes might choose to use third-party reports at the expense of static cues because of the belief that the former make a more reliable basis for expectancy formation than the latter (Horn et al., 2001). The use of such cues has, however, been reported to lead to a reputation bias (Findlay \& Ste-Marie, 2004), whereby an athlete's reputation has a greater influence than their actual performance on a perceiver's judgment of that athlete. Findlay and Ste-Marie found that even when 
there were no differences between figure skaters in terms of actual performance, judges awarded better scores to performers who were known to have a good reputation for skating compared with those whose skating reputation was unknown to the judges. It is vital that future research examine the extent to which athletes' use of third-party reports when forming impressions of coaches can evoke expectancy effects such as reputation bias.

The main limitation of the current study is its failure to account for the entire range of cues that athletes might use when creating initial expectancies of a coach. There are recent indications that individuals in the sport setting are judged in a more complex fashion than the findings of the current study would suggest. For example, the work of Solomon and others (e.g., Becker \& Solomon, 2005; Solomon, 2001) suggests that psychological cues are deemed to be influential during the expectancy formation process. The current study was limited to the examination of observable cues that are not dependent on the availability and subsequent processing of other sources of information. Although psychological cues were excluded from the current investigation, it is clear that further research designed to examine such sources of information is warranted. For example, an interesting avenue for future investigation would be to identify the observable cues athletes use to form expectancies of a coach's psychological characteristics. Moreover, given the impact of psychological information on the impressions that coaches form of athletes' ability, future research should attempt to identify the information sources coaches use to form expectancies of athletes' psychological characteristics.

Multivariate analysis of the data revealed that there were no significant main effects for gender, type of sport, or level of participation of the athlete. Moreover, all interaction effects between the three variables were nonsignificant. Such findings suggest that whether they are male or female, individual or team performers, amateur or elite, athletes generally agree on the informational cues regarded as influential in forming initial expectations of a coach. Although Warr and Knapper's (1968) model suggests that impression formation might be determined according to the perceiver's demographic background, the findings of the current study imply that this contention does not hold for athletes who form impressions of coaches. There remain, however, other factors that might impact such impression formation.

Because the population sample was primarily made up of student athletes of a similar age, it was not possible to investigate the effect of age or background on the cues athletes use to form expectancies of a coach. This would be a valuable area for future scrutiny in an attempt to discover whether other demographic differences between athletes signify the need to revise specific coaching guidelines. If athletes of varying backgrounds or age groups use different cues to help them form impressions of a coach, then a greater understanding of these differences in information selection is essential to ensure that coaches are sufficiently educated and able to adapt their behavior appropriately depending on the target population. Moreover, in addition to perceivers' stable characteristics (e.g., age, cultural background), Warr and Knapper's (1968) model proposes that the perceiver's current state (i.e., the situation they are in, their episodic thoughts and feelings at the time of viewing the target) has the potential to influence impression formation. The perceiver's current state was not accounted for within the current study, signifying another area that future research needs to address. 
The aim of this study was to identify the observable cues that athletes perceive to be most influential when forming initial expectancies of their coach. EFA led to the extraction of a three-factor model, which revealed that dynamic cues (e.g., eye contact, facial expressions, body language) and third-party reports (e.g., coaching experience, success rate, reputation) are rated by athletes as highly influential during impression formation, whereas static cues (e.g., gender, race or ethnicity, age) are deemed to be less relevant sources of information in this context. The findings also proposed that athletes of different gender, type of sport, and level of participation hold similar views regarding the cues deemed influential in evaluating the efficiency of coaching staff. It must be conceded that the current study contains certain limitations. For example, it could be argued that some of the measurement items employed (e.g., items of jewelry, touching behavior) might be too open to athlete interpretation to provide an accurate representation of specific cues that might be used during an athlete's expectancy formation. The current findings, nevertheless, have implications for guidelines of coaching practice and suggest that coaches should be mindful of the way in which athletes perceive particular sources of information. The results of this explorative study suggest that by developing strategies to convey appropriate dynamic behavioral cues (e.g., positive body language) and third-party reports (e.g., limiting the information conveyed to athletes), coaches and their employers will be better equipped to create desirable impressions and expectancies in their athletes.

The next step for research in this area is to empirically test the validity of these models via the manipulation of informational cues and the measurement of athletes' subsequent expectancies of a coach. Furthermore, future study in this area should investigate the accuracy and longevity of such expectancies and the potential they have to affect the coach-athlete relationship. Further research should also attempt to discover whether the cues used by athletes when forming impressions of their coach have the potential to result in erroneous expectancies that might hinder or even enhance the coach-athlete relationship and the performance of both individuals. It is anticipated that such studies will prove valuable in the development of effective coaching guidelines and in facilitating positive coach-athlete interactions.

\section{References}

Argyle, M. (1983). The psychology of interpersonal behaviour (4th ed.). Harmondsworth, UK: Penguin Books.

Becker, A.J., \& Solomon, G.B. (2005). Expectancy information and coach effectiveness in intercollegiate basketball. The Sport Psychologist, 19, 251-266.

Chelladurai, P. (1990). Leadership in sports: A review. International Journal of Sport Psychology, 21, 328-354.

Chen, M., \& Bargh, J.A. (1997). Nonconscious behavioural confirmation processes: The self-fulfilling consequences of automatic stereotype activation. Journal of Experimental Social Psychology, 33, 541-560.

Cook, M. (1971). Interpersonal perception. Harmondsworth, UK: Penguin Education.

Crisfield, P., Cabral, P., \& Carpenter, F. (1999). The successful coach: Guidelines for coaching practice. Leeds, UK: National Coaching Foundation.

DePaulo, B.M. (1992). Nonverbal behaviour and self-presentation. Psychological Bulletin, $111,203-243$. 
Findlay, L.C., \& Ste-Marie, D.M. (2004). A reputation bias in figure skating. Journal of Sport \& Exercise Psychology, 26, 154-166.

Frank, M.G., \& Gilovich, T. (1988). The dark side of self- and social perception: Black uniforms and aggression in professional sports. Journal of Personality and Social Psychology, 54, 74-85.

Garson, G.D. (2006). Factor analysis. Statnotes: Topics in multivariate analysis. Retrieved from N. Carolina St. University, Quantitative Research in Public Administration Web site: http://www2.chass.ncsu.edu/garson/pa765/factor.htm

Greenlees, I., Buscombe, R., Thelwell, R., Holder, T., \& Rimmer, M. (2005). Impact of opponents' clothing and body language on impression formation and outcome expectations. Journal of Sport \& Exercise Psychology, 27, 39-52.

Grisaffe, C., Blom, L.C., \& Burke, K.L. (2003). The effects of head and assistant coaches' uses of humor on collegiate soccer players' evaluation of their coaches. Journal of Sport Behavior, 26, 103-108.

Guyll, M., \& Madon, S. (2003). Trait hostility: The breadth and specificity of schema effects. Personality and Individual Differences, 34, 681-693.

Hash, R.B., Manna, R.K., Vogel, R.L., \& Bason, J.J. (2003). Does physician weight affect perception of health advice? Preventive Medicine, 36, 41-44.

Horn, T.S., Lox, C.L., \& Labrador, F. (2001). The self-fulfilling prophecy theory: When coaches' expectations become reality. In J. Williams (Ed.), Applied sport psychology: Personal growth to peak performance (pp. 68-81). Mountain View, CA: Mayfield.

Jacobs, J.E., \& Eccles, J.S. (1992). The impact of mothers' gender-role stereotypic beliefs on mothers' and children's ability perceptions. Journal of Personality and Social Psychology, 63, 932-944.

Jowett, S., Frost, T., \& Timson-Katchis, M. (April, 2006). Race/ethnicity in the all male coach-athlete relationship: Black footballers' narratives. Poster presentation at BPS Annual Conference, City Hall, Cardiff, UK.

Jussim, L. (1993). Accuracy in interpersonal expectations: A reflection-construction analysis of current and classic research. Journal of Personality, 61, 637-668.

Jussim, L., Coleman, L.M., \& Lerch, L. (1987). The nature of stereotypes: A comparison and integration of three theories. Journal of Personality and Social Psychology, 52, 536-546.

Jussim, L., \& Eccles, J.S. (1992). Teacher expectations II: Construction and reflection of student achievement. Journal of Personality and Social Psychology, 63, 947-961.

Jussim, L., \& Harber, K.D. (2005). Teacher expectations and self-fulfilling prophecies: Knowns and unknowns, resolved and unresolved controversies. Personality and Social Psychology Review, 9, 131-155.

Knapp, M.L., \& Hall, J.A. (2002). Nonverbal communication in human interaction (5th ed.). New York: Wadsworth/Thomson Learning.

Krippendorff, K. (1980). Content analysis: An introduction to its methodology. Newbury Park, CA: Sage.

Lubker, J.R., Watson, J.C., II, Visek, A.J., \& Geer, J.R. (2005). Physical appearance and the perceived effectiveness of performance enhancement consultants. The Sport Psychologist, 19, 446-458.

Merton, R.K. (1948). The self-fulfilling prophecy. The Antioch Review, 8, 193-210.

Miki, H., Tsuchiya, H., \& Nishino, A. (1993). Influence of expectancy of opponents' competence upon information processing of their discrete attributes. Perceptual and Motor Skills, 77, 987-993.

Miller, D.T., \& Turnbull, W. (1986). Expectancies and interpersonal processes. Annual Review of Psychology, 37, 233-256.

Plunkett, B.A., Kohli, P., \& Milad, M.P. (2002). The importance of physician gender in the selection of an obstetrician or a gynecologist. American Journal of Obstetrics and Gynecology, 185, 926-928. 
Razran, G. (1950). Ethnic dislikes and stereotypes: A laboratory study. Journal of Abnormal and Social Psychology, 45, 7-27.

Rentfrow, P.J., \& Gosling, S.D. (2006). Message in a ballad: The role of music preferences in interpersonal perception. Psychological Science, 17, 236-242.

Shields, C.A., Brawley, L.R., \& Martin Ginis, K.A. (2007). Interactive effects of exercise status and observer gender on the impressions formed of men. Sex Roles, 56, 231-237.

Solomon, G.B. (2001). Performance and personality impression cues as predictors of athletic performance: An extension of expectancy theory. International Journal of Sport Psychology, 32, 88-100.

Solomon, G.B., DiMarco, A.M., Ohlson, C.J., \& Reece, S.D. (1998). Expectations and coaching experience: Is more better? Journal of Sport Behavior, 21, 444-455.

Stevens, J. (1996). Applied multivariate statistics for the social sciences. Mahwah, NJ: Lawrence Erlbaum.

Stone, J., Perry, Z.W., \& Darley, J.M. (1997). "White men can't jump": Evidence for the perceptual confirmation of racial stereotypes following a basketball game. Basic and Applied Social Psychology, 19, 291-306.

Tabachnick, B.G., \& Fidell, L.S. (1996). Using multivariate statistics (3rd ed.). New York: Harper Collins.

Turiel, E. (1983). The development of social knowledge: Morality and convention. Cambridge, UK: Cambridge University Press.

Warr, P.B., \& Knapper, C. (1968). The perception of people and events. London: John Wiley \& Sons.

Manuscript submitted: April 1, 2007

Revision received: July 1, 2007 
Copyright of Sport Psychologist is the property of Human Kinetics Publishers, Inc. and its content may not be copied or emailed to multiple sites or posted to a listserv without the copyright holder's express written permission. However, users may print, download, or email articles for individual use. 